\title{
Economic Growth and the Environment: Theory and Facts*
}

\author{
Sherry Bartz \\ Department of Economics \\ University of Miami \\ Box 248126 \\ Coral Gables, FL 33134 \\ and \\ David L. Kelly \\ Department of Economics \\ University of Miami \\ Box 248126 \\ Coral Gables, FL 33134
}

April 22, 2006

\footnotetext{
${ }^{*}$ We would like to thank Claustre Bajona, Carlos Flores, Adrian Peralta, Pedro Gomis-Porqueras, and seminar participants at the University of Central Florida, the University of Miami, and HEC Montréal for comments and suggestions.
} 


\begin{abstract}
Several recent papers propose competing theoretical explanations for the empirical observation of an inverted U-shape relationship between enviromental degradation and per-capita income. We proprose the following test of the theory: calibrate a theoretical model to an already developed economy using information unrelated to the pollution-income curve. Then simulate the model starting from a less developed initial condition and compare the predicted pollutionincome relationship with that in the data. Our results are mixed. Some support exists for the theory that the inverted U-shape results from a corner solution in which less developed countries do not abate pollution. However, pollution peaks at a level of per capita income that is much lower than that observed in the U.S. data.
\end{abstract}




\section{Introduction}

A large literature investigates the relationship between environmental degradation and economic development. For some pollutants, a number of empirical papers (surveys include Copeland and Taylor, 2004; Dasputa, Laplante, Wang, and Wheeler, 2002; Dinda, 2004) find evidence of an inverted U-shape: pollution levels rise and then fall as income increases. This result, popularly known as the Environmental Kuznets Curve (EKC), has been called into question by a number of authors (see for example Stern, 2003). These authors show the EKC result is not robust to various changes in the specification of the econometric model. Theoretical models prove the existence of an inverted U-shape pollution-income curve, ${ }^{1}$ but provide differing explanations for why the curve occurs. Further, none of these theoretical models have been tested. Thus no bridge between the theoretical and empirical models exists. This research uses calibration and simulation to test a growth model with emissions as a factor of production and environmental quality as a normal good. We also test the idea that the EKC results from a corner solution in which pollution initially rises with economic development because no pollution is abated, then falls with development as abatement grows. Although we sometimes find existence of a inverted U-shape, the model predicts for all pollutants that emissions peak at an income level lower than that in the U.S. data.

The use of calibration to analyze the pollution-income relationship has some advantages. In particular, calibration requires only data from a developed economy. Thus we avoid missing or low quality data in developing countries, and do not have to worry about country specific effects that might be present if the model were instead estimated using data from a panel of countries. Further, our calibration exercise is a direct test of a theoretical model, as well as a test of the idea that the inverted U-shape pollution-income curve arises because countries initially choose a corner solution with no pollution abatement. Therefore, unlike most empirical

\footnotetext{
${ }^{1}$ A large number of theoretical explanations also exist. See Dinda (2004) for a survey.
} 
papers we directly test a model without using reduced-form equations, which obscure exactly how and why the inverted U-shape occurs. Also, our results provide some guidance to empirical research.

Finally, this paper is of general interest in that we provide one of the few rigorous calibrations of a model of growth and the environment. All parameters are calibrated so that the model matches a variety of long run average features of the data. Thus the theory is consistent with the data in a way that simple numerical examples of theoretical models generally are not. ${ }^{2}$ We hence provide a framework for a more rigorous test of theoretical environmental economics models at the national level. Rather than ask if a numerical example exists that is analytically consistent with observed facts (for some parameters, the model has an inverted U-shape), the test we propose asks if a numerical example consistent with a variety of features of the data generates also the observed fact in question (for a particular set of parameters, the model has an inverted U-shape that peaks at a point reasonably close to that in the data).

Levinson and Israel (2003) provide the only other existing direct test of the theory. They utilize the World Values Survey, a poll of about 70,000 residents in 48 countries to ascertain marginal willingness to pay (MWTP) for a clean environment. Using this largely qualitative data, Levinson and Israel investigate whether the patterns of willingness to pay conform to those predicted by John and Pecchenino (1994) and Stokey (1998). They find conclusive evidence that MWTP declines with GDP per capita in rich countries, suggesting that if MWTP has decreased, the environment must have already improved. They also reveal some semblance of a peak in MWTP, which implies that a high level of environmental degradation is correlated with the peak in MWTP (if the environment is bad, people are willing to pay for abatement). However, their analysis is limited by low-quality survey data.

The structure of this paper is as follows. First, we provide a list of existing theoretical

\footnotetext{
${ }^{2}$ A few theoretical models give numerical examples. For example, Stokey (1998) has a numerical example in which pollution peaks at about $50 \%$ of the steady state capital stock.
} 
explanations and empirical regularities. Next, we develop our model. We calibrate the model with U.S. emissions data for five pollutants. The time series data indicate that emissions of all pollutants in our sample peak late, after the U.S. was nearly completely developed. We then computationally examine the shape of the pollution-income curve predicted by the model for each pollutant. The model predicts an inverted U-shape, but pollution peaks at an income level lower than that in the U.S. data.

\section{Empirical Regularities}

We examine the following ambient pollutants: sulfur dioxide $\left(\mathrm{SO}_{2}\right)$, carbon monoxide $(\mathrm{CO})$, nitrogen oxide $\left(\mathrm{NO}_{2}\right.$ and $\mathrm{NO}$, collectively $\left.\mathrm{NO}_{x}\right)$, particulates $\left(\mathrm{PM}_{10}\right.$ and $\mathrm{PM}_{2.5}$, collectively PM), volatile organic compounds (VOC), and airborne lead. We choose these pollutants based on the availability of compliance cost data.

The existing empirical literature, which mostly uses data from a panel of countries, show pollutant-specific results for a variety of ambient, water and soil pollutants. In general, most research in this area entails using fixed effects and random effects estimation of quadratic, loglinear, log-quadratic and/or cubic-polynomial pollution-income relationships. Emissions or pollutant concentrations (either urban or national) are regressed on GDP per capita as well as other variables such as time trend, population density and site-related variables. The reducedform equation adopted by most of the empirical studies is assumed to capture the structural model in which income influences technology, the composition of GDP and environmental policy, and how changes in these factors in turn affect environmental pressure. An important issue in the empirical literature is the estimation of the location of the turning point; i.e., the income level at which emissions peak. Dozens of studies exist; here we present a few standard ones. $^{3}$

Grossman and Krueger (1995) estimate a cubic reduced-form relationship between per

\footnotetext{
${ }^{3}$ See Dinda (2004) for a survey.
} 
capita income and various environmental indicators. They use Global Environmental Monitoring System (GEMS) pollution concentration data on $\mathrm{SO}_{2}$, heavy particulates, and smoke (their classification for smaller particulates). For most pollutants, they find an inverted-U result, where pollution peaks at a relatively low GDP per capita. Bandopadhyay and Shafik (1992), using a polynomial with log income and ambient levels of $\mathrm{SO}_{2}$ and suspended particulate matter (SPM), estimate pollution-income curves with a data set of 149 countries. They also find an inverted-U shape, where pollution peaks at a relatively low GDP per capita. Selden and Song (1994), employing a quadratic pollution-income relationship, utilize a panel of national emissions data on $\mathrm{SPM}, \mathrm{SO}_{2}, \mathrm{NO}_{x}$, and $\mathrm{CO}$. They estimate slightly higher turning point income levels. Selden and Song (1994) speculate this is because ambient pollution concentrations are likely to decline before aggregate emissions, due to the population concentrations in cities, the ability to install higher smokestacks, etc. Like in Selden and Song (1994), Panayotou (1993) measures pollutants in terms of emissions per capita on a national basis. They obtain inverted U-shape results for SPM, $\mathrm{SO}_{2}$, and $\mathrm{NO}_{x}$. Hilton and Levinson (1998) estimate the relationship between lead emissions and income. They find an inverted U-shape pollution-income relationship with a turning point that is sensitive to both functional form (polynomial and log-quadratic) and time period (pre and post 1983). For post 1983, they find a statistically significant peak. Table 4 gives the turning points for all studies in constant US dollars. $^{4}$

In a more recent study, Stern and Common (2001) ask whether the basic econometric model is adequately specified; i.e., whether the model is subject to omitted variables bias. They use a larger and more globally representative $\mathrm{SO}_{2}$ sample (31 annual observations on each of 73 developed and developing countries) than previous $\mathrm{SO}_{2} \mathrm{EKC}$ studies. They estimate a logarithmic quadratic pollution-income curve for world, OECD and non-OECD samples. They find that the turning point for $\mathrm{SO}_{2}$ depends on the sample employed; for the OECD countries,

\footnotetext{
${ }^{4}$ All dollar figures in this paper are in year 2000 constant US dollars.
} 
$\$ 11,250$, and for the world, $\$ 123,188$.

Harbaugh, Levinson, and Wilson (2002) also question the specification of the basic econometric model. They update and clean up the data employed by Grossman and Krueger (1995); i.e., their results benefit from 10 years of additional observations, more cities, and revisions of some of the original observations. In addition, the authors test the sensitivity of the pollutionincome relationship to alternative functional forms, additional covariates and changes in the nations, cities and years sampled. They include variables describing national income, political structure, investment, trade and population density, as well as control variables that account for location of monitoring stations. They find the results to be highly sensitive to these changes and conclude that the jury is still out on whether sufficient empirical support exists for an inverted U-shaped relationship. By adding 10 years and 25 cities to Grossman and Krueger's data set, Harbaugh et. al. find $\mathrm{SO}_{2}$ emissions peak at $\$ 29,587$. Depending on the length of the GDP time-lag, explanatory variables, year dummies, structural form, and outlier removal, estimated $\mathrm{SO}_{2}$ peaks range from $\$ 27,700$ to $\$ 96,507$. When the authors limit their $\mathrm{SO}_{2}$ sample to countries with income greater than $\$ 11,787$, they find no evidence of the inverted U-shape. They also conduct the same types of regressions for airborne lead and $\mathrm{NO}_{x}$. According to Harbaugh, et. al., due to smaller sample sizes the results are generally less statistically significant. Yet, $\mathrm{NO}_{x}$ appears to peak at $\$ 7,956$ and airborne lead at $\$ 21,070$.

Citing the data availability and accuracy problems with GEMS data, List and Gallet (1999) and Millimet, List, and Stengos (2003) use utilize pooled U.S. state-level data from EPA (2000b). ${ }^{5}$ List and Gallet (1999) use quadratic and cubic specifications popular in previous EKC studies, as well as a semiparametric model that allows for state-level EKC heterogeneity. For parametric models, they estimate $\mathrm{NO}_{x}$ peak emissions at incomes from $\$ 13,071$ to $\$ 16,275$,

\footnotetext{
${ }^{5} \mathrm{~A}$ problem with this data is that the EPA changed its state level measurement methods in 1985, so emissions estimations fall into two major regimes: 1929-1984 and 1985-1994. Emissions estimates in the first regime are derived from the top down; information at the national level is used to derive individual U.S. states' emissions. In 1985, the EPA began to measure emissions at the plant or county level, aggregating these totals to form state-level emissions.
} 
and for semiparametric models, incomes from $\$ 19,224$ to $\$ 26,541$. For $\mathrm{SO}_{2}$, they estimate peak emissions at incomes from $\$ 30,408$ to $\$ 34,055$ (parametric) and at $\$ 19,920$ to $\$ 29,415$ (semiparametric). Millimet, List, and Stengos (2003) test the traditional parametric regression (quadratic and cubic specifications) against a more flexible semiparametric approach. Millimet, et. al., using a parametric cubic specification, estimate peak $\mathrm{NO}_{x}$ emissions at $\$ 13,072$ for the full data set and $\$ 15,961$ for the $1985-94$ data. For $\mathrm{SO}_{2}$, they find statistically insignificant results for the full data set and a peak at $\$ 24,790$ for the $1985-94$ data set. Utilizing the semiparametric approach, they find peaks at $\$ 18,120\left(\mathrm{NO}_{x}\right)$ and $\$ 12,080\left(\mathrm{SO}_{2}\right)$. They also test the validity of the parametric specification and determine they can statistically reject parametric models in favor of the semiparametric approach. Specifically, they note that the estimated parametric peak for $\mathrm{SO}_{2}$ is very sensitive to modeling assumptions.

Figure 1 plots the U.S. time series pollution data. We use U.S. national emissions data from 1947-1998 from EPA (2000b). We aggregate $\mathrm{CO}$ and $\mathrm{NO}_{x}$ emissions since the cost data is not disaggregated between these two pollutants. Unfortunately, collection methods change over time as new sources of emissions are added. To resolve this problem, we assume that if a new source is added in period $t$, the change in emissions for that source from $t-1$ to $t$ equals the average change from all other sources. We can then estimate emissions in period $t-1$ and so on back to the initial year. ${ }^{6}$ For all pollutants except particulates, new sources are relatively small. Thus, the results are not sensitive to how and if we modify the data to deal with new sources. All pollutants show some evidence of an inverted-U shape over time, although particulates and lead are mostly decreasing. When emissions are plotted against per capita income, lead is even less clearly inverted-U shaped.

Table 4 gives the level of per-capita income at which pollution peaks. The income data comes from the National Income and Product Accounts (NIPA) of the U.S. Department of

\footnotetext{
${ }^{6}$ Other ideas are less attractive. Excluding new sources would introduce a downward bias on national emissions and bias some parameters (for example, lower national emissions would cause an upward bias in the parameter which measures preferences for environmental quality).
} 
Commerce. As detailed in Section 5.1 below, changes to income data were made so that the data is consistent with the theoretical model developed below. Table 4 shows that emissions peaked late in development for the U.S., ranging from an income of $\$ 20,983$ per capita for particulates to $\$ 35,091$ for $\mathrm{SO}_{2}$. As seen in Table 4, these values are more consistent with the later empirical literature, which predicts emissions peak at a relatively high income. These results are also broadly consistent with Brock and Taylor (2003), who note pollution in the U.S. peaks in the 1970 s for most pollutants. ${ }^{7}$ The peaks are somewhat higher than U.S. state level studies, but as Selden and Song (1994) note, the emissions peak using national data tends to be higher than the emissions peak using more disaggregated data. In addition, our modifications to the GNP data include adding imputed services from government capital and durable goods, which increases GNP by as much as $18 \%$. Table 4 shows that all categories except particulates peaked between 1970 and 1973. Particulates peaked in 1950. Therefore, we conclude that the stylized fact in the U.S. data is that the pollution-income curve has an inverted U-shape, and that emissions peak at a relatively late stage of development.

\section{Development and the Environment: Theory}

As the theory goes, in the first stage of industrialization, people are more interested in eating than in breathing clean air. Communities are too poor to pay for abatement and environmental regulation is correspondingly weak or non-existent. As income rises, industry becomes cleaner and marginal utility of consumption falls, indicating that people value the environment more highly. Also, regulatory institutions become more effective. Along the curve, pollution levels off in the middle-income range and then falls toward pre-industrial levels in wealthy societies.

Thus, according to Dasputa, et. al. (2002), certain assumptions must be made to achieve the inverted U-shape. Namely, with an increase in income, there must be constant or falling marginal utility of consumption, rising disutility of pollution or rising marginal damage of

\footnotetext{
${ }^{7}$ The results are also broadly consistent with Portney (1990). Further, Deacon and Norman (2004) show that $\mathrm{SO}_{2}$ was decreasing since the 1970 s for a variety of wealthy countries.
} 
pollution (environmental quality is a normal good), and increasing marginal cost of abatement. Also, public agencies must exist that regulate pollution with full information about the benefits and costs of pollution control. Pollution may be reduced by abatement activity or by an increasingly "cleaner" composition of GDP and consumption. Dinda (2004) divides the large number of theoretical explanations into five broad categories. Here we review only three categories and formally test one (in Section 8 we discuss how the other two explanations could be tested).

Andreoni and Levinson (2001) and Kelly (2003) focus on the cost of abatement. According to Kelly (2003), simple convexity in costs of abatement are sufficient for the marginal cost of abatement to rise along the growth path. By modeling environmental quality as a normal good, marginal damages rise with income. The trade-off between these two effects determines the shape of the pollution-income curve. Andreoni and Levinson (2001) suppose that abatement has increasing returns to scale. They show that after the economy achieves a certain minimum size, it is worthwhile to pay the initial or fixed costs and begin abatement.

Cropper and Griffiths (1994), Jones and Manuelli (2001) and others focus on institutional explanations. Countries with strong property rights and institutions typically are more wealthy and are better able to regulate emissions. Hence, a panel of countries with varying degrees of institutional strength could produce an inverted U-shape: pollution increases with growth among poor countries with weak institutions and decreases with growth in wealthy countries with strong institutions.

Stokey (1998) and John and Pecchenino (1994) provide models with pollution-income curves that are inverted U-shaped, peaking when the optimum switches from a corner solution with zero abatement to an interior optimum with positive environmental investment. John and Pecchenino (1994) use an overlapping-generations framework in which environmental quality is a stock resource. While consumption degrades the environment, investment in the environment by the younger generation improves the environment bequeathed to future 
generations. In Stokey (1998), pollution is proportional to GDP, but the proportion can be reduced by a control technology. A "dirty" method of production is used if income is below a critical threshold, while progressively cleaner methods are utilized as income rises above that level. Below the threshold, pollution increases with income. Above the threshold, total pollution depends on the elasticity of the marginal utility of consumption goods. For an elasticity greater than one, the model has an inverted-U pollution-income curve. An increase in income raises consumption, which reduces the marginal utility of consumption. Therefore, the marginal benefit of emissions (increased consumption via increased GDP) falls. Further, pollution is proportional to income and utility is convex in pollution, so an increase in income raises the marginal damage of pollution.

\section{Model}

The model is a generalization of Kelly (2003), which allows for exogenous labor-augmenting and pollution-reducing technological change. The model does not have increasing returns to abatement, and implicitly assumes institutions exist which can regulate pollution. The model does have a constraint that abatement is non-negative. Thus we will test whether the non-negativity constraint idea explains the shape and the timing of the pollution-income curve in the U.S. data.

The population of $L_{t}$ identical households have preferences over end-of-the-period environmental quality $N_{t+1}$, consumption $\frac{C_{t}}{L_{t}}$, and leisure equal to one less hours worked $h_{t}$ in each period. Capital letters denote aggregate quantities. Preferences are given by the utility function:

$$
U\left[\frac{C_{t}}{L_{t}}, N_{t+1}, h_{t}\right]=\alpha \log \left(\frac{C_{t}}{L_{t}}\right)+(1-\alpha) \log \left(N_{t+1}\right)-\gamma h_{t} .
$$

We use the Hansen (1985) indivisible labor assumption, which implies linear aggregate disutility of labor. A particular issue is the assumption that utility is separable in consumption, leisure and environmental quality. Strong complementarity between consumption and envi- 
ronmental quality would tend to make environmental quality more appealing at high incomes, when consumption and leisure are highest, and less appealing at low incomes. ${ }^{8}$

A constant returns to scale technology exists that produces GDP $Q_{t}$ from capital $K_{t}$ and productivity-augmented total hours $h_{t} L_{t} A_{t}$. Here $A_{t}$ is the level of technology, which grows exogenously at rate $\phi$. Population grows at rate $\eta$. The production technology is such that:

$$
Q_{t}=K_{t}^{\psi}\left(h_{t} L_{t} A_{t}\right)^{1-\psi}
$$

Unabated pollution is an exogenous proportion $\frac{1}{B_{t}}$ of GDP. Let $u_{t}$ denote the fraction of emissions abated, then $\frac{1-u_{t}}{B_{t}}$ is the emissions intensity of GDP and emissions, $E_{t}$, is:

$$
E_{t}=\left(1-u_{t}\right) \frac{Q_{t}}{B_{t}}
$$

The cost of emissions abatement is $C\left(u_{t}\right) Q_{t}$. Hence GDP net of abatement costs, $Y_{t}$, is:

$$
Y_{t}=\left(1-C\left(u_{t}\right)\right) Q_{t}
$$

We assume a convex cost function:

$$
C\left(u_{t}\right)=1-\left(1-u_{t}\right)^{\varepsilon}
$$

Using Equations (2), (3), (4), and (5) to substitute out for $Q_{t}$ and $u_{t}$ implies GDP net of abatement costs is Cobb-Douglas:

$$
Y_{t}=F\left(K_{t}, B_{t} E_{t}, h_{t} L_{t} A_{t}\right)=K_{t}^{\theta}\left(B_{t} E_{t}\right)^{\varepsilon}\left(h_{t} L_{t} A_{t}\right)^{1-\theta-\varepsilon}
$$

Here $\theta=\psi(1-\varepsilon)$ is the capital share and $\varepsilon$ can thus be interpreted as the emissions share. We assume emissions, $E_{t}$, is stationary. Therefore, the exogenous growth rate of $B_{t}$ must equal the growth rate of GDP, $\eta+\phi(1+\eta)$. Exogenous growth of $B_{t}$ is assumed to capture technological change in abatement and compositional changes in GDP.

\footnotetext{
${ }^{8}$ Given that utility is separable, the pollution-income curve is not very sensitive to labor supply. We have endogenous labor supply in the model to make the calibration easier.
} 
Let capital depreciate at rate $\delta_{k}$. The resource constraint then sets consumption plus net investment equal to production net of abatement costs:

$$
C_{t}=Y_{t}+\left(1-\delta_{k}\right) K_{t}-K_{t+1}
$$

Environmental quality is a decreasing function of the stock of pollution, $M_{t+1}$ :

$$
N_{t+1}=\widehat{M}-M_{t+1}
$$

Here $\widehat{M}$ is the maximum sustainable pollution stock. We assume the pollution concentration decays at a constant rate $\delta_{m}$. Therefore the stock of pollution accumulates according to:

$$
M_{t+1}=E_{t}+\left(1-\delta_{m}\right) M_{t}
$$

The objective function of the social planner is to maximize lifetime utility of all households:

$$
V=\max _{C_{t}, K_{t}, E_{t}, h_{t}}\left\{\sum_{t=0}^{\infty} \beta^{t} L_{t}\left[U\left(\frac{C_{t}}{L_{t}}, N_{t+1}, h_{t}\right)\right]\right\} .
$$

The problem can be normalized with economic variables written in per productivity unit terms. Let the units of emissions be such that $A_{0} L_{0}=B_{0}$, let $k_{t}=\frac{K_{t}}{L_{t} A_{t}}$ and similarly for $c_{t}$ and $y_{t}$ and let $\hat{\beta}=\beta(1+\eta)<1$. Then the social planning problem is:

$$
v=\max _{\left\{c_{t}, E_{t}, h_{t}\right\}} \sum_{t=0}^{\infty} \hat{\beta}^{t}\left[U\left(c_{t}, N_{t+1}, h_{t}\right)\right]
$$

subject to:

$$
\begin{aligned}
& c_{t}=F\left(k_{t}, E_{t}, h_{t}\right)+\left(1-\delta_{k}\right) k_{t}-(1+\eta)(1+\phi) k_{t+1} \\
& N_{t+1}=\widehat{M}-M_{t+1} \\
& M_{t+1}=E_{t}+\left(1-\delta_{m}\right) M_{t} .
\end{aligned}
$$

In addition, maximum and minimum emissions exist corresponding to $u=0$ and $u=1$ :

$$
0 \leq E_{t} \leq k_{t}^{\frac{\theta}{1-\varepsilon}} h_{t}^{\frac{1-\theta-\varepsilon}{1-\varepsilon}}
$$


If $u=0$, we have a corner solution with no abatement and maximum emissions, $E_{t}=$

$k_{t}^{\frac{\theta}{1-\varepsilon}} h_{t}^{\frac{1-\theta-\varepsilon}{1-\varepsilon}}$ and the non-negativity constraint on abatement given by Equation (14) is binding. The recursive version of the problem is:

$$
v(k, M)=\max _{k^{\prime}, h, M^{\prime}}\left\{\begin{array}{c}
U\left[f(k, E, h)+\left(1-\delta_{k}\right) k-(1+\eta)(1+\phi) k^{\prime}, \widehat{M}-M_{t+1}, h_{t}\right]+ \\
\hat{\beta} v\left(k^{\prime}, M^{\prime}\right)
\end{array}\right\} .
$$

The maximization is subject to (13) and (14).

\section{Calibration}

\subsection{Data}

In contrast to the panel studies, we focus solely on U.S. data. Since we want an "out-ofsample" test of the EKC theory, we exclude developing countries as we don't calibrate to the observed pollution-income curve. The economic data, gleaned from the U.S. Department of Commerce, Federal Reserve, and Bureau of Labor Statistics, is standard. All sources are in the References Section. A number of manipulations were made to make these data consistent with the model. For example, durable goods "consumption" is actually consistent with investment in the model, and the stock of inventories is consistent with the model's definition of capital. These modifications are standard in the literature (see for example Cooley and Prescott, 1995) and are fully described in Bartz (2006). Emissions data is described in Section 2.

To calibrate the environmental parameters, we require data on emissions, compliance costs and control rates. Our environmental cost and control rate data is harvested from EPA (1990). This report is attractive for our purpose as the authors divide compliance spending by pollutant category. The categories include: (1) particulates, (2) $\mathrm{SO}_{2}$, (3) $\mathrm{NO}_{x}$ and $\mathrm{CO}$, (4) lead, and (5) VOCs.

Compliance cost data exists for years 1972-1998; however, no reports are available after 1990, so compliance costs for 1991-1998 are from EPA projections. The EPA reports both capital and flow cost data, but our model has only flow costs. To convert capital costs into 
flows, we assume stationary and mobile capital (e.g. cars) are amortized over lives of 20 years and 10 years, respectively. We are implicitly assuming no capital compliance costs occurred prior to 1972. The interest rate used for the amortization is identical to the steady state interest rate derived from the economic data, around $8 \%$. The amortization is in accordance with EPA methods, except they use a 7\% interest rate. Full details are available in Bartz (2006).

Table 10.2 of EPA (1990) gives control rate data for the period 1984-1988. We also calibrate using $\mathrm{SO}_{2}$ permit price data, gleaned from EPA (2000a). Finally, atmospheric depreciation rates are from air pollution textbooks (Stern, 1976; Stern, Boubel, Turner, and Fox, 1984).

\subsection{Assignment of Model Parameters}

Most of the economic parameters are calibrated in an identical manner to the previous literature (see for example Cooley and Prescott, 1995). In general, we choose the parameters to match certain long run average features of the data. We do not use the observed dynamic relationship between emissions and income in the data to calibrate any of the parameters, since we are testing this aspect of the model.

We calibrate the rate of growth in population so that the rate of growth in population in the model economy matches the average rate of growth in population in the data over the sample period. Similarly, the rate of growth of technology is chosen so that the steady state rate of growth in per capita GDP, $g_{y}$, in the model economy matches the average rate of growth in per capita GDP in the data. We define investment, $X$, as:

$$
X_{t}=K_{t+1}-\left(1-\delta_{k}\right) K_{t}
$$

Since in the steady state investment, GDP, and capital all grow at the same rate, the steady state investment to capital ratio, $\frac{X}{K}$, is:

$$
\frac{X}{K}=(1+\eta)(1+\phi)-\left(1-\delta_{k}\right) .
$$


Using (15), we choose $\delta_{k}$ so that the model economy matches the investment to capital ratio of the data.

Let $\rho=\frac{1-\beta}{\beta}$ be the pure rate of time preference. The first order condition for optimal investment at the steady state is then:

$$
\left[(1+\rho)(1+\phi)-\left(1-\delta_{k}\right)\right] k=\theta y
$$

Equation (16) implies $\theta$ is the share of income accruing to capital owners since the left hand side is the return on capital. Let $I_{t}$ denote capital income, then we choose $\theta=\frac{I}{Y}$, so that the share of income accruing to capital owners in the model matches the average share of income accruing to capital owners in the data. ${ }^{9}$ Then using (16), $\rho$ is chosen so that the steady state capital to GDP net of abatement costs ratio in the model economy matches the data. We thus assign the parameters $\rho, \phi, \eta, \delta_{k}$, and $\theta$ using the standard technique of Cooley and Prescott (1995). Table 1 gives the calibrated values of the economic parameters. ${ }^{10}$

We use scientific studies to calculate the rate of decay of the stock of pollution, $\delta_{m}$. We classify pollutants that survive in the atmosphere for less than a year as flows $\left(\delta_{m}=1\right)$. Particulates, $\mathrm{SO}_{2}, \mathrm{NO}_{x}$, lead and VOCs all last in the atmosphere for less than a week. $\mathrm{CO}$ has an atmospheric residence time of one to three months. One type of VOC, hydrocarbons, has a residence time of 16 years. Since we cannot separate the spending on hydrocarbons from other VOCs, we use an average residence time of eight years. ${ }^{11}$ Table 3 gives the calibrated values of $\delta_{m}$.

We explore three alternatives for the calibration of the emissions share, $\varepsilon$. Ideally, the emissions share may be computed using observed tax rates or permit prices if the government

\footnotetext{
${ }^{9}$ The capital share depends on $y$, output net of compliance spending, rather than total output, $q$. Since $y$ is pollutant specific, the capital share is pollutant specific. This is an artifact of running the model separately for each pollutant, rather than considering all pollutants together, an assumption we make for computational simplicity. In practice, because compliance spending is a small fraction of GDP, the capital share and most other economic parameters are nearly identical across pollutants.

${ }^{10}$ Differences between Table 1 and Cooley and Prescott (1995) arise due to NIPA data revisions and because we use a different time period.

${ }^{11} \mathrm{EPA}(2000 \mathrm{~b})$ estimate $43-50 \%$ of VOC emissions are hydrocarbons.
} 
uses a market-based regulation instrument. The planning problem of Section 4 can be decentralized into a competitive equilibrium in which the marginal product of emissions equals the tax rate per unit of emissions (or the price of a tradable permit that allows one unit of emissions). Thus, with $\tau$ denoting the tax rate (or permit price), we have the following:

$$
\tau=\varepsilon B z K^{\theta}(B E)^{\varepsilon-1} H^{1-\varepsilon-\theta}
$$

Equation (17) then implies:

$$
\frac{\tau E}{Y}=\varepsilon
$$

Hence we choose $\varepsilon$ so that the share of income spent on emissions taxes (or permits) equals the average share of income spent on permits or taxes in the data. It is important to note we only use data from a developed economy at the steady state to calculate $\varepsilon$. In the transitional dynamics, changes in the marginal product of emissions as a country develops are important for the shape of the pollution-income curve (see Kelly, 2003). However, we reiterate that our calibration only utilizes GDP data from a fully developed economy, so $\varepsilon$ is not chosen to match the peak of the pollution-income curve in any way.

Unfortunately among the pollutants in the data only $\mathrm{SO}_{2}$ regulation is market-based. For the remaining pollutants (and $\mathrm{SO}_{2}$, for comparison) we use EPA environmental compliance cost data to calibrate the emissions share. From Equation (5):

$$
\varepsilon=\frac{\log \left(1-C\left(u_{t}\right)\right)}{\log \left(1-u_{t}\right)}
$$

We thus set $\varepsilon$ so that the elasticity governing the sensitivity of compliance costs to the control rate matches the average elasticity in the data. Unfortunately, the EPA provides control rate data only for the period 1984-1988, so this method of calibration relies on a small data set.

A third method involves combining Equations (3) and (5):

$$
\frac{B E}{Q}=\left(1-C\left(u_{t}\right)\right)^{\frac{1}{\varepsilon}}
$$


Hence $\varepsilon$ equals:

$$
\varepsilon=\frac{\log \left(1-C\left(u_{t}\right)\right)}{\log \left(\frac{B_{0}[(1+\phi)(1+\eta)]^{t} E}{Q}\right)} .
$$

Note that since $B$ grows at the same rate as GDP and emissions is stationary, $B E / Q$ is stationary. Given the ratio $B E / Q$, we set $\varepsilon$ so that long run average environmental compliance spending in the model matches long run average compliance cost spending in the data.

We have then three calibration strategies, each with some advantages and disadvantages. Choosing $\varepsilon$ to match spending on pollution permits has the advantage of relying on higherquality market data. However, permit data is available only for $\mathrm{SO}_{2}$. Calibrating $\varepsilon$ to match compliance spending requires construction of an estimate of exogenous improvements emissions intensity, which is highly variable. Calibrating $\varepsilon$ to match control rate data does not require information on emissions intensity improvements, but data is available only for five years. All methods yield reasonably similar results (see Table 3 ). Section 7 shows that a large change in $\varepsilon$ is needed to affect the results, so for the remainder of the paper we employ the control rate calibration.

An example may help the reader understand the calibration. Consider that in 1986 lead emissions dropped from 22.9 to 7.3 million short tons. In that year, compliance spending was nearly unchanged at $0.007 \%$ of GDP, and the control rate increased from $91 \%$ to $96 \%$. Using the second method, the 1986 observation indicates almost all lead emissions were controlled at little cost, and therefore the technology for controlling lead emissions appears very efficient, and thus $\varepsilon$ is small. Given that lead emissions fell dramatically without any increase in costs, it is clear that the exogenous part of emissions intensity $1 / B_{1996}$ fell dramatically. However, the model assumes a constant rate of growth in exogenous emissions intensity. Given an average improvement in emissions intensity and a large decline in emissions, the denominator in (20) falls and $\varepsilon$ needs to be larger to match the 1986 cost data. ${ }^{12}$ Thus in 1986 the cost strategy

\footnotetext{
${ }^{12}$ That regulations changed is not relevant, since $\varepsilon$ measures only technological cost of reducing emissions.
} 
overestimates $\varepsilon$ because it does not account for the unusual fall in emissions intensity. Relying on the control rate data avoids this problem, but, again, that data is only available for five years.

Let subscripts on functions denote derivatives. The first order condition for optimal emissions at the steady state is:

$$
\left((1+\rho)-(1+\eta)\left(1+\delta_{m}\right)\right) U_{c}(c, \widehat{M}-M, h) f_{E}(k, E, h)=U_{N}(c, \widehat{M}-M, h)(1+\rho) .
$$

Hence:

$$
\left((1+\rho)-(1+\eta)\left(1+\delta_{m}\right)\right) \varepsilon \frac{Y}{C} \alpha=(1+\rho) \frac{E}{\widehat{M}-M}(1-\alpha)
$$

Equation (21) equates the marginal benefits and marginal costs of emissions at the steady state. We therefore set $\alpha$ so that steady state emissions in the model matches long run average emissions in the data.

The first order condition for optimal hours worked at the steady state is:

$$
\gamma=U_{c}(c, \widehat{M}-M, h) f_{h}(k, E, h)
$$

Hence:

$$
\gamma=\frac{Y}{C} \frac{\alpha(1-\theta-\varepsilon)}{h}
$$

Given the consumption to GDP net of abatement costs ratio implied by the model, we calibrate $\gamma$ so that the steady state fraction of time spent working in the model matches the data, which is $h=0.20 .^{13}$

It is typical to assume the U.S. economy is fluctuating around a deterministic steady state. Hence, the steady state can be taken as the long run average of U.S. data. Since the model generates a stationary level of emissions, we expect that in the data emissions

\footnotetext{
${ }^{13}$ McGrattan (1994) finds $h=0.27$. Our methodology is similar except that we use the establishment survey, which reports lower hours (and thus higher productivity) than the household survey, especially in the 1990s.
} 
are also fluctuating around a steady state. Emissions of most pollutants, however, are either trending downward or have been stationary only recently. Therefore, we must choose a suitable time period during which emissions of each pollutant is stationary. Particulates have been roughly constant since 1980 and lead since 1986. Thus we use 1980-1998 and 1986-1998 data to calculate the stationary level of emissions and abatement costs for particulates and lead, respectively. However, $\mathrm{SO}_{2}, \mathrm{NO}_{x} / \mathrm{CO}$, and VOCs have only leveled off recently, if at all. $\mathrm{SO}_{2}$ and $\mathrm{NO}_{x} / \mathrm{CO}$ are roughly constant over the period 1995-1998, while VOCs are roughly constant over the period of 1996-1998. For all pollutants, a time series forecast indicates a steady state very close to current levels. We therefore use 1995-1998 data to calculate the stationary level of emissions and abatement costs for $\mathrm{SO}_{2}$ and $\mathrm{NO}_{x} / \mathrm{CO}$ and 1996-1998 data for VOCs. ${ }^{14}$ The model then implicitly assumes the U.S. is transitioning to a balanced growth path over the period 1952 to the stationary period with $k, y$, and abatement spending increasing and $E$ decreasing. This matches the data, with $k$ and $y$ increasing $10-20 \%$ over the transition period. ${ }^{15}$

We have thus chosen nine parameters to match various features of the U.S. economy. Five economic parameters depend only on the environmental data in that $y$ differs from $q$, which makes no difference up to two significant digits. One parameter is chosen from scientific studies. The remaining three parameters are derived using only data from a developed economy (1980 and after) and are in fact chosen to match the hours, emissions, and environmental compliance spending data of the recent U.S. economy. An interesting question is the prediction of the model for transition economies, which we turn to next.

\footnotetext{
${ }^{14}$ Writing a model for which emissions are decreasing along the balanced growth path poses theoretical problems. In particular, such a model requires exogenous emissions intensity to fall faster than exogenous labor productivity rises. Thus, emissions saving technological change would continue at a constant rate, despite having marginal benefits which approach zero.

${ }^{15}$ Most of the increase in $k$ and $y$ occur prior to 1980 . We therefore use the period 1980-1998 to calculate the economic ratios.
} 


\section{Results}

The model was solved using the method of Kelly and Kolstad (1999), which computes nonlinear approximations of the value function and decision rules $E(k, M), k^{\prime}(k, M)$, and $h(k, M)$. Per capita income in the empirical literature corresponds to income prior to abatement spending, $q=\frac{Q}{L A}=k^{\psi} h^{1-\psi}$. Hence the decision rule may be written as $E\left(q^{\frac{1}{\psi}} h^{\frac{\psi-1}{\psi}}, M\right)$. For the flow pollutant categories (particulates, $\mathrm{SO}_{2}, \mathrm{NO}_{x} / \mathrm{CO}$, and lead), the decisions are independent of $M$; therefore, the pollution-income curve $E(q)$ measures emissions only as a function of income. $E(q)$ shares a similar shape with $E(k)$ and thus also with the pollution-income curve generated from time series data starting from a less-developed initial condition ( $k_{0}$ equal to a small positive number). For the stock pollutant category, VOCs, the effect of an increase in income on emissions (or the end of the period pollution stock $M^{\prime}$ ) varies with $M$, so we report several versions of the pollution-income curve.

The model exhibits increasing and then decreasing levels of emissions for all flow pollutants as income increases, suggesting an inverted-U relationship (see Figures 2-5). Specifically, for sufficiently low incomes (low capital stocks), our model displays a corner solution. When income is low, no abatement exists. The planner prefers to set abatement equal to zero in order to increase GDP and thus increase consumption. Hence, the constraint that emissions cannot exceed emissions with zero abatement (Equation 14) binds. Then, as the capital stock increases past a certain level, abatement rises above zero and emissions decline.

For the stock pollutant VOCs, the shape of the pollution-income curve varies according to how pollution is measured. No matter the value of $M$, emissions have an inverted U-shape as a function of income. If we generate a time series starting from a sufficiently small $k_{0}$ and $M_{0}$ and plot emissions as a function of $q$, the result is again an inverted-U shape (see Figure 6). However, if we use the same time series, but plot $M$ as a function of $q$, then the pollution-income curve is increasing. The current stock of pollution is a function of all previous 
emissions decisions and thus all previous incomes. Therefore, the stock will tend increase with income even if emissions are a decreasing or inverted-U function of current income. ${ }^{16}$

Analytically, for flow pollutants, the optimal emissions are determined from the tradeoff between the marginal benefit of emissions, equal to the marginal product of emissions times the marginal utility of consumption, and the marginal cost of emissions, equal to the marginal utility of environmental quality. For our calibrated values, the marginal utility of consumption falls with income whereas the marginal utility of environmental quality is relatively constant. Hence the unconstrained pollution-income curve is decreasing. Further, the emissions constraint is concave in capital. Together, these facts imply that the pollutionincome curve will be inverted U-shaped and the constraint that emissions cannot be negative will be binding for sufficiently low incomes (see Figure 7). Indeed, we prove this theoretically in Appendix B. For the stock pollutant VOCs, it turns out that emissions continue to increase for a short income interval after the constraint is no longer binding (the slope of the unconstrained pollution-income curve becomes less than the slope of the constraint, but still is positive). Emissions then decline once income exceeds this interval. Thus the nature of the cost function, rather than the non-negative abatement constraint, explains the inverted-U shape for VOCs. ${ }^{17}$

Although we garner an inverted U-shape, the downward turn occurs very early in development. Table 4 shows that the peak emissions occur between 10 and 13 percent of the steady state capital stock, whereas in the data the peak occurs between 77 and 90 percent of the steady state capital stock. Why does the model predict emissions peak so early in development? In the steady state U.S. economy, compliance spending is small relative to GDP. Steady state abatement for all pollutants is $70-74 \%$ of uncontrolled emissions. Yet, steady state compliance spending is well under 1\% of GDP for each pollutant. Therefore the calibration chooses a small $\varepsilon$ to reflect that abatement is relatively inexpensive in the data. But if pollution is

\footnotetext{
${ }^{16}$ Kelly (2003) show this result is a possibility in numerical examples.

${ }^{17}$ Kelly (2003) shows the non-negativity constraint is not necessary for an inverted-U in a simpler version of this model.
} 
inexpensive to abate, then countries can afford to abate at a relatively low income. Indeed, it is apparent from the calibration that the puzzle in the data is why the U.S. waited until 1970 to begin significant abatement, given that abatement is so inexpensive. This is most striking for lead emissions. The U.S. reduced lead emissions from 255 million short tons in 1972 to 4.5 million short tons in 1992, but compliance spending rose from essentially zero to only $0.015 \%$ of GDP. Given that lead emissions could be reduced so inexpensively, why was compliance spending still essentially zero in 1972 , when the U.S. GDP per capita was $\$ 32,396 ?$

Emissions would also peak later in development if the parameter governing household preferences for environmental quality, $1-\alpha$, were lower. However, the calibration requires households have some preference for environmental quality, otherwise emissions would decline little and end up at a higher steady state than observed in the U.S. data.

Alternative parameter values exist that can generate an emissions peak identical to the data (see Section 7), but these parameter values are unrealistic. They imply emissions reduction is more costly or that households have weaker preferences for environmental quality than is apparent in the U.S. data.

Turning now to the empirical studies, our U.S. data is more consistent with the later empirical studies, which predict emissions peak at a relatively high income, if at all. According to our model, emissions peak early in development, which is more consistent with the earlier empirical studies that predict emissions peak for middle income countries. Still, comparisons are difficult because the literature focuses on GDP per capita as the state variable rather than GDP per productivity unit, which is the state variable of our model. If the data is cross sectional and all countries have the same technology, then our model maps one-to-one into the empirical literature by simply multiplying GDP per productivity unit by $A_{t}$. However, most empirical studies use panel data, so two data points with nearly the same income per capita but different years could represent significantly different places on the transition path.

Our results provide some guidance to the empirical literature. Our state variable is GDP 
per productivity unit rather than GDP per capita. In the empirical literature, the regression is of the form:

$$
E_{t}=\beta_{0}+g\left(\frac{Y_{t}}{L_{t}} ; \beta_{1}\right)+h\left(t ; \beta_{2}\right)+\zeta_{t}
$$

Thus the time trend may pick up a mixture of time-related effects: productivity advances, compositional changes, emission efficiency innovations, and any structural breaks that may have occurred (e.g. a shift in preferences in the 1970s). In contrast, our model allows only one explanation for the EKC, and so the relationship between emissions and time is more restrictive:

$$
E_{t}=g\left(\frac{1}{A_{t}} \cdot \frac{Y_{t}}{L_{t}} ; \beta_{1}\right)+\zeta_{t}
$$

Or if productivity data is not available:

$$
E_{t}=g\left(\frac{1}{A_{0}(1+\phi)^{t}} \cdot \frac{Y_{t}}{L_{t}} ; \beta_{1}\right)+\zeta_{t} .
$$

Figures 2-6 show the results of estimating a quadratic version of Equation (24). ${ }^{18}$ Thus, the theory in this paper points toward using income per productivity unit without a time trend as a regressor in reduced form regressions.

\section{Sensitivity Analysis}

Here we perform sensitivity analysis to check robustness of the results and to gain information about what parameters most affect the peak emissions. Each row of Table 5 is a simulation that holds all parameters constant at the values determined by the particulates calibration except for the given parameter. The critical value is the value of the given parameter that results in an emissions peak equal to the emissions peak in the U.S. data, about $77.25 \%$ of the steady state capital stock for particulates. Most of the parameters have little effect on the emissions peak. The consumption share $\alpha$ and emissions share $\varepsilon$ are clearly the most

\footnotetext{
${ }^{18}$ The quadratic term is negative and significant at the $5 \%$ level for all pollutants.
} 
important parameters, since these affect the central trade-off between environmental quality and consumption. A higher $\alpha$ means the marginal utility of consumption is higher, and thus optimal unconstrained emissions rise across the development path. Higher unconstrained emissions in turn implies that the abatement non-negativity constraint becomes non-binding at a later stage of development (a larger $k$ ). Graphically, this corresponds to a shift to the right of the optimal emissions curve in Figure 7. A higher $\varepsilon$ means the marginal product of emissions is greater, increasing the incentive to emit regardless of development and causing the unconstrained optimal emissions curve to shift to the right. However, it is important to note that increasing $\alpha$ and $\varepsilon$ also cause steady state emissions to rise. If we change $\alpha$ or $\varepsilon$ so that the model predicts an emissions peak of $77.25 \%$ of the steady state capital stock, then the model predicts steady state emissions that are about three times the levels observed in the U.S. data.

The most important economic parameter is $\gamma$. Increasing preferences for leisure (increasing $\gamma$ ) decreases hours and thus income. Lowering income increases the marginal utility of consumption, which in turn increases incentives to emit and hence causes emissions to peak later. Decreasing hours also tightens the constraint that requires abatement to be positive (see Equation 14). This also causes emissions to peak later. However, to get emissions to peak as in the U.S. data requires increasing $\gamma$ to a point such that steady state hours are $27 \%$ below that in the U.S. data.

Increasing $\delta_{k}, \eta$, and $\phi$ lower income per-productivity unit available for consumption and abatement. The marginal utility of consumption thus falls and optimal emissions rise, which causes emissions to peak later. Increasing $\rho$ reduces investment, freeing up income to be spent on consumption and abatement. This causes optimal emissions to fall and emissions to peak earlier. However, reducing investment also reduces the steady state capital stock. Thus emissions peak at a lower capital stock, but at a higher percentage of the steady state capital stock for $\rho$. Increasing $\theta$ also reduces investment, but the trade-off between the reduction in 
steady state capital stock and the earlier absolute peak in emissions is non linear.

Table 5 shows that economic parameter values exist for which the model replicates the U.S. emissions experience, where emissions peaked late in development. However, these parameter values are unrealistic: they are contrary to intuition and imply the model will not perform well in a variety of other standard dimensions.

To examine interaction effects among the parameters, we randomly select a sample of parameter vectors from an assumed distribution, solve the model for each parameter vector, and calculate the emissions peak. We then compute statistics from the resulting emissions peak data. To keep the computations manageable, we allow only the two parameters that are most uncertain and most strongly affect the emissions peak, $\alpha$ and $\varepsilon$, to vary. We assign a very conservative distribution for each parameter. We assume $\alpha$ and $\varepsilon$ are such that the lower bound is the baseline value and the upper bound is the value that results in steady state emissions that are twice that of the U.S. data when all other parameters are held at their baseline values. Thus:

$$
\left[\begin{array}{l}
\alpha \\
\varepsilon
\end{array}\right] \sim U\left[\begin{array}{c}
0.9238,0.9612 \\
0.0014,0.0028
\end{array}\right] .
$$

We ran 100 simulations, the results of which are summarized in Table 6 . We reject the hypothesis that the emissions peak is greater than or equal to $50 \%$ of the steady state capital stock given the assumed parameter uncertainty with $95 \%$ confidence. We therefore conclude that the results of the model are robust to reasonable parameter uncertainty.

\section{Conclusions/Implications}

Our results show increasing and then decreasing pollution emissions as income rises. At first, abatement is equal to zero. People are more interested in eating than environmental quality. Then, preferences for environmental quality come into play and the abatement constraint ceases to bind. Indeed, if we remove the requirement that abatement must be non-negative, we find a decidedly negative relationship between income and emissions. 
The fact that abatement is initially equal to zero (a corner solution) is in accord with Stokey (1998) and others. However, the model predicts that emissions peak early in development, largely because abatement is inexpensive relative to GDP, according to U.S. emissions and compliance spending data. Thus the results imply an interesting puzzle: why did the U.S. wait until the 1950s to begin significant abatement for particulates and until the 1970s for all other pollutants?

Although we test only one theoretical explanation, the corner solution, other standard theories are not likely to fare better. Consider the institutional explanation of Jones and Manuelli (1995). The U.S. clearly had many functioning institutions common to developed countries prior to 1970 (justice system, etc.). Why did the EPA not arise until 1970? Or consider the theory of Andreoni and Levinson (2001) that increasing returns to abatement exist. Since total compliance costs, including fixed costs, are small, why the U.S. require such a high income to make it optimal to pay the fixed costs and begin abatement?

Less standard explanations may hold some promise. Adding uncertainty either over the cost of abatement or the damage from pollution could explain some of the delays. Similarly, a significant technological innovation could have reduced the cost of abatement in the 1970s. Or perhaps a shift in preferences for environmental quality in the 1970s caused the observed increase in abatement. These ideas are more difficult to test, however, and also do not necessarily imply an inverted-U shape pollution-income curve. ${ }^{19}$ Finally, the peak could be linked to increases in the price of energy during the 1970s.

Another possibility is that the corner solution is the correct idea, but some modifications of the model are needed. For example, the functional form of the cost or utility functions could be incorrect. The modified cost or utility function would have to raise emissions only for low and middle income stages of development, however. Also, our model assumes emissions

\footnotetext{
${ }^{19}$ Deacon and Norman (2004) look at time series data for a variety of countries and find a similar empirical result to ours for the U.S. They speculate that the downward trend in emissions since the 1970 s may be a result of a shift in preferences, but note that other explanations may be observationally equivalent.
} 
are stationary. Given the decrease in emissions over the past twenty years even in developed countries, perhaps a better choice is to assume the rate of decline in emissions intensity is larger than the growth rate of GDP. However, this implies that research and development which increases the productivity of emissions would continue despite returns to innovation that are much lower than the returns to innovations that increase the productivity of labor.

Empirical work of late has called into question whether the relationship between growth and pollution is a simple inverted-U. Our results show that existing theory may need substantial modifications to explain the U.S. experience with growth and pollution. The relationship between economic growth and the environment is apparently considerably more complicated than once thought. Nonetheless, the effect of economic growth on the environment is an important problem and is therefore deserving of continued research.

\section{References}

Andreoni, J., and A. Levinson, 2001, "The Simple Analytics of the Environmental Kuznets Curve," Journal of Public Economics, 80, 269-86.

Bandopadhyay, S., and N. Shafik, 1992, "Economic Growth and Environmental Quality: Time Series and Cross-Country Evidence," Discussion Paper World Bank Policy Research Working Paper WPS 904, World Bank, Washington, DC.

Bartz, S., 2006, "Calibrating a Model of Growth and the Environment," University of Miami.

Board of Governors of the Federal Reserve, 2001, "Flow of Funds Accounts, Balance Sheet of the United States," Discussion paper, Federal Reserve Report.

Brock, W., and M. S. Taylor, 2003, "Economic Growth and the Environment: Matching the Stylized Facts," Department of Economics, University of Wisconsin-Madison Working Paper. 
Bureau of Labor Statistics, 2002, "Survey of Productivity and Costs," Discussion paper, BLS Report.

Cooley, T., and E. Prescott, 1995, "Economic Growth and Business Cycles," in Thomas Cooley (ed.), Frontiers of Business Cycle Research . chap. 1, Princeton University Press, Princeton, NJ.

Copeland, B., and M. S. Taylor, 2004, "Trade, Growth, and the Environment," Journal of Economic Literature, 42, 7-71.

Cropper, M., and C. Griffiths, 1994, "The Interaction of Populations, Growth, and Environmental Quality," American Economic Review, 84, 250-254.

Dasputa, S., B. Laplante, H. Wang, and D. Wheeler, 2002, "Confronting the Environmental Kuznets Curve," Journal of Economic Perspectives, 16, 147-168.

Deacon, R. T., and C. S. Norman, 2004, "Does the Environmental Kuznets Curve Explain How Individual Countries Behave?," University of California, Santa Barbara Working Paper.

Dinda, S., 2004, "Environmental Kuznets Curve Hypothesis: A Survey," Ecological Economics, $49,431-55$.

Energy Information Administration, 2000a, "Estimated Emissions of Greenhouse Gases," Discussion Paper Table 12.1, EIA Report, http://www.eia.doe.gov/emeu/aer/txt/stb1201.xls.

Energy Information Administration, 2000b, "Ozone Depleting Substances and Criteria Pollutants, 1980-1999," Discussion Paper Table 12.5, EIA Report, http://www.eia.doe.gov.

EPA, 1990, "Environmental Investments: The Costs of a Clean Environment," Discussion Paper EPA-230-11-90-083, Environmental Protection Agency Report.

EPA, 2000a, "Acid Rain Program: Annual Progress Report, 2000," Discussion Paper EPA430-R-01-008, Environmental Protection Agency Report, http://www.epa.gov. 
EPA, 2000b, "National Air Pollutant Trends 1900-1998," Discussion Paper EPA-454/R-00-002, Environmental Protection Agency Report.

Grossman, G., and A. Krueger, 1995, "Economic Growth and the Environment," Quarterly Journal of Economics, 112, 353-77.

Hansen, L., 1985, "Indivisible Labor and the Business Cycle," Journal of Monetary Economics, $16,309-327$.

Harbaugh, W., A. Levinson, and D. Wilson, 2002, "Reexamining the Empirical Evidence for an Environmental Kuznets Curve," Review of Economics and Statistics, 84, 541-551.

Hilton, F., and A. Levinson, 1998, "Factoring the Environmental Kuznets Curve: Evidence From Automotive Lead Emissions," Journal of Environmental Economics and Management, $35,126-41$.

John, A., and R. Pecchenino, 1994, "An Overlapping Generations Model of Growth and the Environment," Economic Journal, 104, 1393-1410.

Jones, L., and R. Manuelli, 2001, "Endogenous Policy Choice: The Case of Pollution and Growth," Review of Economic Dynamics, 4, 369-405.

Jones, L. E., and R. E. Manuelli, 1995, "A Positive Model of Growth and Pollution Controls," Discussion Paper 5205, National Bureau of Economic Research Working Paper.

Kelly, D. L., 2003, "On Environmental Kuznets Curves Arising From Stock Externalities," Journal of Economic Dynamics and Control, 27, 1367-1390.

Kelly, D. L., and C. D. Kolstad, 1999, "Bayesian Learning, Pollution, and Growth," Journal of Economic Dynamics and Control, 23, 491-518.

Levinson, A., and D. Israel, 2003, "Green Preferences: Testable Empirical Implications of the Growth and Environmental Literature," Georgetown University. 
List, J. A., and C. A. Gallet, 1999, "The Environmental Kuznets Curve: Does One Size Fit All?," Ecological Economics, 31, 409-23.

McGrattan, E., 1994, "A Progress Report on Business Cycle Models," FED Minneapolis Quarterly Review, pp. 2-16.

Milgrom, P., and C. Shannon, 1994, "Monotone Comparative Statics," Econometrica, 62, $157-180$.

Millimet, D. L., J. A. List, and T. Stengos, 2003, "The Enviromental Kuznets Curve: Real Progress or Misspecified Models?," Review of Economics and Statistics, 85, 1038-47.

Panayotou, T., 1993, "Empirical Tests and Policy Analysis of Environmental Degradation at Different Stages of Economic Development," Working Paper WP238, Technology and Employment Programme, Interantional Labor office, Geneva.

Portney, P. R., 1990, "Air Pollution Policy," in P. R. Portney (ed.), Public Policies for Environmental Protection, Resources for the Future, Washington, DC.

Selden, T., and D. Song, 1994, "Environmental Quality and Development: Is There a Kuznets Curve for Air Pollution Emissions?," Journal of Environmental Economics and Management, 27, 147-162.

Stern, A., R. Boubel, D. Turner, and D. Fox, 1984, Fundamentals of Air Pollution, Academic Press, London.

Stern, A. C., 1976, Air Pollution, Vol 1: Air Pollutants, Their Transformation and Transport, Academic Press, New York.

Stern, D., and M. Common, 2001, "Is There an Environmental Kuznets Curve for Sulfur?," Journal of Environmental Economics and Management, 41, 162-178. 
Stern, D. I., 2003, "The Rise and Fall of the Environmental Kuznets Curve," Discussion Paper 0302, Rensselaer Working Papers in Economics.

Stokey, N., 1998, "Are There Limits to Growth?," International Economic Review, 39, 1-31.

Summers, R., and A. Heston, 1991, "The Penn World Tables (Mark 5): An Expanded Set of International Comparisons, 1950-88," Quarterly Journal of Economics, 106, 327-68.

US Dept. of Commerce, 1998, "Fixed Reproducible Tangible Wealth in the US: Revised Estimates for 1995-7 and Summary Estimates for 1925-1997," Discussion paper, BEA Report.

US Dept. of Commerce, 2001, "National Income and Product Accounts of the US," Discussion paper, BEA Report. 


\section{Appendix A: Tables}

\begin{tabular}{|l|r|}
\hline Parameter & \multicolumn{1}{|l|}{ Value } \\
\hline$\rho$ & 0.071 \\
\hline$\theta$ & 0.402 \\
\hline$\delta_{k}$ & 0.046 \\
\hline$\eta$ & 0.011 \\
\hline$\phi$ & $0.018-0.019$ \\
\hline
\end{tabular}

Table 1: Economic parameter values. Small differences (less than 0.001 for $\phi$, less than 0.0001 for all other economic paramters) exist in the economic parameters across pollutants.

\begin{tabular}{|l|r|r|r|r|r|}
\hline & Particulates & \multicolumn{1}{|c|}{$\mathrm{SO}_{2}$} & $\mathrm{NO}_{x} / \mathrm{CO}$ & \multicolumn{1}{l|}{ Lead } & \multicolumn{1}{l|}{ VOCs } \\
\hline Emissions & 0.0434 & 0.0194 & 0.1179 & 0.0052 & 0.0199 \\
\hline Compliance Spending & 0.151 & 0.1812 & 0.0221 & 0.0154 & 0.0622 \\
\hline Abatement & 66.34 & 29.61 & 68.76 & 99.87 & 39.62 \\
\hline Steady State Period & $1980-1998$ & $1995-1998$ & $1995-1998$ & $1986-1998$ & $1996-1998$ \\
\hline
\end{tabular}

Table 2: Average yearly emissions (short gigatons), compliance spending (\% of GDP), and abatement (\% of unabated emissions) in steady state time period.

\begin{tabular}{|l|c|c|c|c|}
\hline & \multicolumn{5}{|c|}{ Control Rate Calibration } \\
\hline Parameter & $\varepsilon$ & $\alpha$ & $\gamma$ & $\delta_{m}$ \\
\hline $\mathrm{PM}$ & 0.00139 & 0.924 & 3.640 & 1 \\
\hline $\mathrm{SO}_{2}$ & 0.00516 & 0.756 & 2.960 & 1 \\
\hline $\mathrm{NO}_{x} / \mathrm{CO}$ & 0.00019 & 0.989 & 3.905 & 1 \\
\hline $\mathrm{Pb}$ & 0.00002 & 0.998 & 3.945 & 1 \\
\hline $\mathrm{VOCs}$ & 0.00123 & 0.894 & 3.525 & 0.125 \\
\hline & \multicolumn{5}{|c|}{ Cost Calibration } \\
\hline $\mathrm{PM}$ & 0.00091 & 0.949 & 3.741 & 1 \\
\hline $\mathrm{SO}_{2}$ & 0.00145 & 0.918 & 3.615 & 1 \\
\hline $\mathrm{NO}_{x} / \mathrm{CO}$ & 0.00017 & 0.989 & 3.908 & 1 \\
\hline $\mathrm{Pb}^{\mathrm{V}}$ & 0.00015 & 0.990 & 3.911 & 1 \\
\hline $\mathrm{VOCs}^{5}$ & 0.00046 & 0.958 & 3.780 & 0.125 \\
\hline $\mathrm{SO}_{2}$ & \multicolumn{5}{|c|}{ Permit Calibration } \\
\hline
\end{tabular}

Table 3: Environmental Parameter values. 


\begin{tabular}{|l|r|r|r|r|r|}
\hline & \multicolumn{5}{|c|}{ Pollutant } \\
\hline Empirical Studies & $\mathrm{PM}$ & $\mathrm{SO}_{2}$ & $\mathrm{NO}_{x} / \mathrm{CO}$ & $\mathrm{Pb}$ & VOCs \\
\hline GK & $\$ 9,011$ & $\$ 5,967$ & & & \\
\hline SS & $\$ 15,221$ & $\$ 12,786$ & $\$ 8,767-\$ 16,560$ & & \\
\hline SC & & $\$ 123,188$ & & & \\
\hline HL & & & & $\$ 12,420$ & \\
\hline HLW & & $\$ 27,700-\$ 96,507$ & $\$ 7,956$ & $\$ 21,070$ & \\
\hline U.S. Empirical Studies & & & & & \\
\hline LG & & $\$ 19,920-\$ 34,055$ & $\$ 13,071-\$ 26,541$ & & \\
\hline MLS & & $\$ 12,080-\$ 24,790$ & $\$ 13,072-\$ 18,120$ & & \\
\hline Our Data (US\$) & $\$ 20,983$ & $\$ 35,091$ & $\$ 34,296$ & $\$ 34,296$ & $\$ 32,396$ \\
\hline Our Data $(\% \bar{k})$ & $77.25 \%$ & $90.22 \%$ & $86.75 \%$ & $83.53 \%$ & $83.53 \%$ \\
\hline Our Results & $12.6 \%$ & $12.7 \%$ & $12.5 \%$ & $10.0 \%$ & $15.5 \%$ \\
\hline
\end{tabular}

Table 4: Emissions peaks for selected empirical studies, for our U.S. data, and for our model. All dollar values are in constant year 2000 dollars. Empirical studies are GK, Grossman and Krueger (1995), SS, Selden and Song (1994), SC, Stern and Common (2001), HL, Hilton and Levinson (1998), LG, List and Gallet (1999) and MLS, Millimet, et. al. (2003) HLW, Harbaugh, Levinson, and Wilson (2002). Our U.S. GNP data is modified by adding imputed services from government capital and durable goods. The percentages are capital levels at which emissions peak divided by the steady state capital, $\bar{k}$.

\begin{tabular}{|l|r|r|c|l|}
\hline Parameter & Base Value & Critical Value & Error & E-peak(parameter) \\
\hline$\varepsilon$ & 0.00139 & 0.004 & $E: \quad+302 \%$ & increasing \\
\hline$\alpha$ & 0.924 & 0.974 & $E: \quad+300 \%$ & increasing \\
\hline$\gamma$ & 3.640 & 9.392 & $h:-27.2 \%$ & decreasing \\
\hline$\rho$ & 0.071 & 0.753 & $r:+867 \%$ & increasing \\
\hline$\theta$ & 0.402 & none & & inverted-U \\
\hline$\delta_{k}$ & 0.046 & 0.144 & $X / K:+228$ & increasing \\
\hline$\eta$ & 0.011 & none & & increasing \\
\hline$\phi$ & 0.018 & 0.109 & $g_{y}:+589 \%$ & increasing \\
\hline
\end{tabular}

Table 5: The critical value is the parameter value where emissions peak at 77.25 percent of the steady state capital stock. The error is the difference between the model steady state value and the average of steady state U.S. data which the parameter was calibrated to. The last column indicates how the emissions peak varies with the parameter. 


\begin{tabular}{|l|r|r|r|}
\hline Statistic & \multicolumn{1}{|c|}{ Value } & & \\
\hline number & 100 & & \\
\hline mean & $46.0 \%$ & & \\
\hline standard deviation & $19.5 \%$ & & \\
\hline median & $43.9 \%$ & & \\
\hline maximum & $106.4 \%$ & & \\
\hline minimum & $17.6 \%$ & $95 \%$ Confidence Interval \\
\hline Hypothesis & Result & lower bound (\%) & upper bound (\%) \\
\hline peak=77.25 & reject & 44.4 & 52.1 \\
\hline peak $\geq 50$ & reject & $-\infty$ & 49.2 \\
\hline
\end{tabular}

Table 6: Statistics are from a data set of emissions peaks as a percentage of the steady state capital stock.

\section{Appendix B: Theoretical Pollution-Income Relationship}

In this appendix, we show theoretically that, for the flow case, unconstrained emissions are decreasing in the capital stock, and hence that unconstrained pollution decreases as a country develops. We then establish how the constraint changes with the capital stock to establish the theoretical pollution-income curve. The results use the supermodularity results of Milgrom and Shannon (1994).

First, let $s^{\prime}=-(1+\eta)(1+\phi) k^{\prime}$, then the optimization problem is to maximize:

$$
H\left(k, E, h, s^{\prime}\right) \equiv U\left[f(k, E, h)+(1-\delta) k+s^{\prime}, \widehat{M}-E\right]-\gamma h+\hat{\beta} v\left(\frac{s^{\prime}}{-(1+\eta)(1+\phi)}\right)
$$

Let $k^{m}$ and $E^{m}$ denote the maximum sustainable capital and emissions, and let $x=\left[E, h, s^{\prime}\right]$. Define $T=\left[0, k^{m}\right]$ as the set of all sustainable capital stocks, and a set $\Omega$ as:

$$
\Omega=\left\{x \mid 0 \leq h \leq 1,0 \leq E \leq E^{m},-k^{m} \leq s^{\prime} \leq 0\right\}
$$

Then $T$ is a partially ordered set and $\Omega$ is a lattice under the component-wise ordering $\geq$. Notice that we are considering the unconstrained problem only and thus do not consider constraints on maximum and minimum emissions, other than sustainability.

The next step is to show the optimization problem is sub-modular. Milgrom and Shannon (1994) establish that $H$ is sub modular as a function of $\left\{E, h, s^{\prime}\right\}$ if and only if the cross partial 
derivatives are all negative. We have:

$$
\begin{aligned}
H_{E s^{\prime}}\left(k, E, h, s^{\prime}\right) & =U_{c c}(., .) f_{E}(k, E, h)<0 \\
H_{h s^{\prime}}\left(k, E, h, s^{\prime}\right) & =U_{c c}(., .) f_{h}(k, E, h)<0 \\
H_{E h}\left(k, E, h, s^{\prime}\right) & =U_{c}(., .) f_{E h}(k, E, h)+U_{c c}(., .) f_{E}(k, E, h) f_{h}(k, E, h) \\
& =U_{c}(., .)\left[\varepsilon(1-\theta-\varepsilon) \frac{y}{E h}-\frac{-U_{c c}(., .) c}{U_{c}(., .)} \frac{\varepsilon(1-\theta-\varepsilon) y^{2}}{c E h}\right] \\
& =\varepsilon(1-\theta-\varepsilon) U_{c}(., .) \frac{y}{E h}\left[1-\frac{y}{c}\right]<0
\end{aligned}
$$

The above inequality holds since consumption is less than income. Hence $H$ is sub modular.

It remains to show that $H$ has decreasing differences in $k$. Milgrom and Shannon (1994) show that $H$ has decreasing differences if and only if the cross partial derivatives with respect to the decision variables and $k$ are negative. We have:

$$
\begin{aligned}
H_{k s^{\prime}}\left(k, E, h, s^{\prime}\right) & =U_{c c}(., .)\left(f_{k}(k, E, h)+1-\delta_{k}\right)<0 \\
H_{E k}\left(k, E, h, s^{\prime}\right) & =U_{c}(., .) f_{E k}(k, E, h)+U_{c c}(., .) f_{E}(k, E, h)\left(f_{k}(k, E, h)+1-\delta_{k}\right) \\
& =U_{c}(., .)\left[\varepsilon \theta \frac{y}{E k}-\frac{-U_{c c}(., .) c}{U_{c}(., .)} \frac{\varepsilon y}{E c}\left(\frac{\theta y}{k}+1-\delta_{k}\right)\right] \\
& =U_{c}(., .) \frac{y \varepsilon}{E k}\left[\theta-\frac{\left(\theta y+\left(1-\delta_{k}\right) k\right)}{c}\right] \\
& =U_{c}(., .) \frac{y \varepsilon}{E k}\left[\theta\left(1-\frac{y+\left(1-\delta_{k}\right) k}{c}\right)-\frac{(1-\theta)\left(1-\delta_{k}\right) k}{c}\right] \\
& <U_{c}(., .) \frac{y \varepsilon \theta}{E k c}\left[c-\left(y+\left(1-\delta_{k}\right) k\right)\right]<0
\end{aligned}
$$

Here the last inequality holds since consumption is less than wealth. Finally,

$$
\begin{aligned}
H_{k h}\left(k, E, h, s^{\prime}\right) & =U_{c}(., .) f_{k h}(k, E, h)+U_{c c}(., .) f_{h}(k, E, h)\left(f_{k}(k, E, h)+1-\delta_{k}\right) \\
& =U_{c}(., .)\left[(1-\theta-\varepsilon) \theta \frac{y}{h k}-\frac{-U_{c c}(., .) c}{U_{c}(.,)} \frac{(1-\theta-\varepsilon) y}{h c}\left(\frac{\theta y}{k}+1-\delta_{k}\right)\right] \\
& =U_{c}(., .) \frac{(1-\theta-\varepsilon) y}{h k}\left[\theta\left(1-\frac{y+\left(1-\delta_{k}\right) k}{c}\right)-\frac{(1-\theta)\left(1-\delta_{k}\right) k}{c}\right] \\
& <U_{c}(., .) \frac{y(1-\theta-\varepsilon) \theta}{h k c}\left[c-\left(y+\left(1-\delta_{k}\right) k\right)\right]<0
\end{aligned}
$$


Hence $H$ has decreasing differences. Therefore, $E, h$, and $s^{\prime}$ are all decreasing functions of $k$. Equation (14) implies:

$$
E \leq k^{\psi} h(k)^{1-\psi} \equiv u b(k)
$$

Since $h$ is a decreasing function of $k$, the emissions bound may be increasing or decreasing for a given $k$. However, $u b(0)=0$ and $f_{h}(k, E, 0)=\infty$ implies $u b(k)>0$ for $k>0$. Since the upper bound is a continuous function, it follows that there exists a $\widetilde{k}>0$ such that $u b(k)$ is increasing in $k$ over the interval $[0, \widetilde{k}]$.

Unconstrained emissions are decreasing and non-negative, and the upper bound on emissions is increasing for $k$ sufficiently small and satisfies $u b(0)=0$. Hence the constrained optimal pollution-capital curve cannot be strictly decreasing. If unconstrained emissions are everywhere greater than the upper bound, the pollution-capital curve is increasing. If unconstrained emissions drop below the upper bound, then the pollution-capital curve will be an inverted U-shape with abatement equal to zero over some interval of capital stocks $[0, k]$, as in John and Pecchenino (1994) and Stokey (1998). Figure 9 depicts these results for the particulates case. The upper bound is increasing and concave, and the unconstrained emissions eventually drop below the upper bound, creating the inverted U-shape.

\section{Appendix C: Figures}




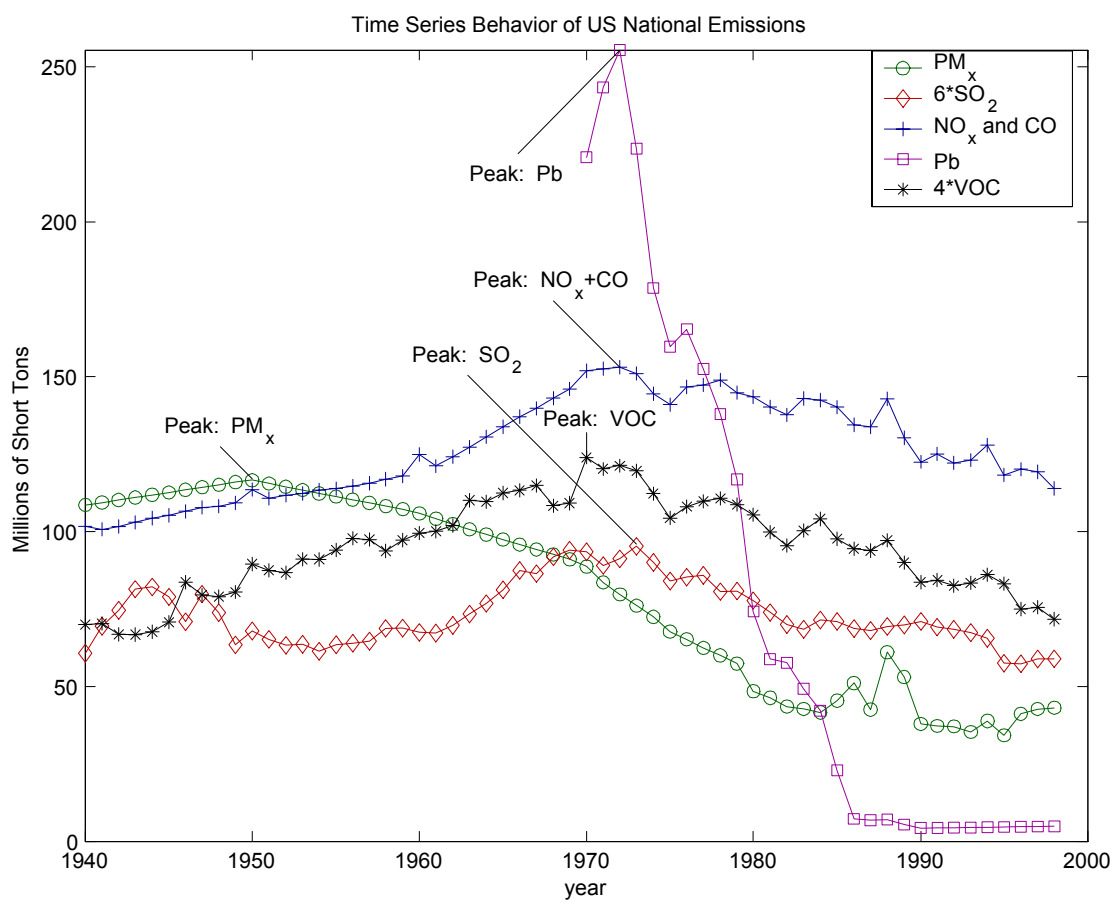

Figure 1: Time series of U.S. national emissions data.

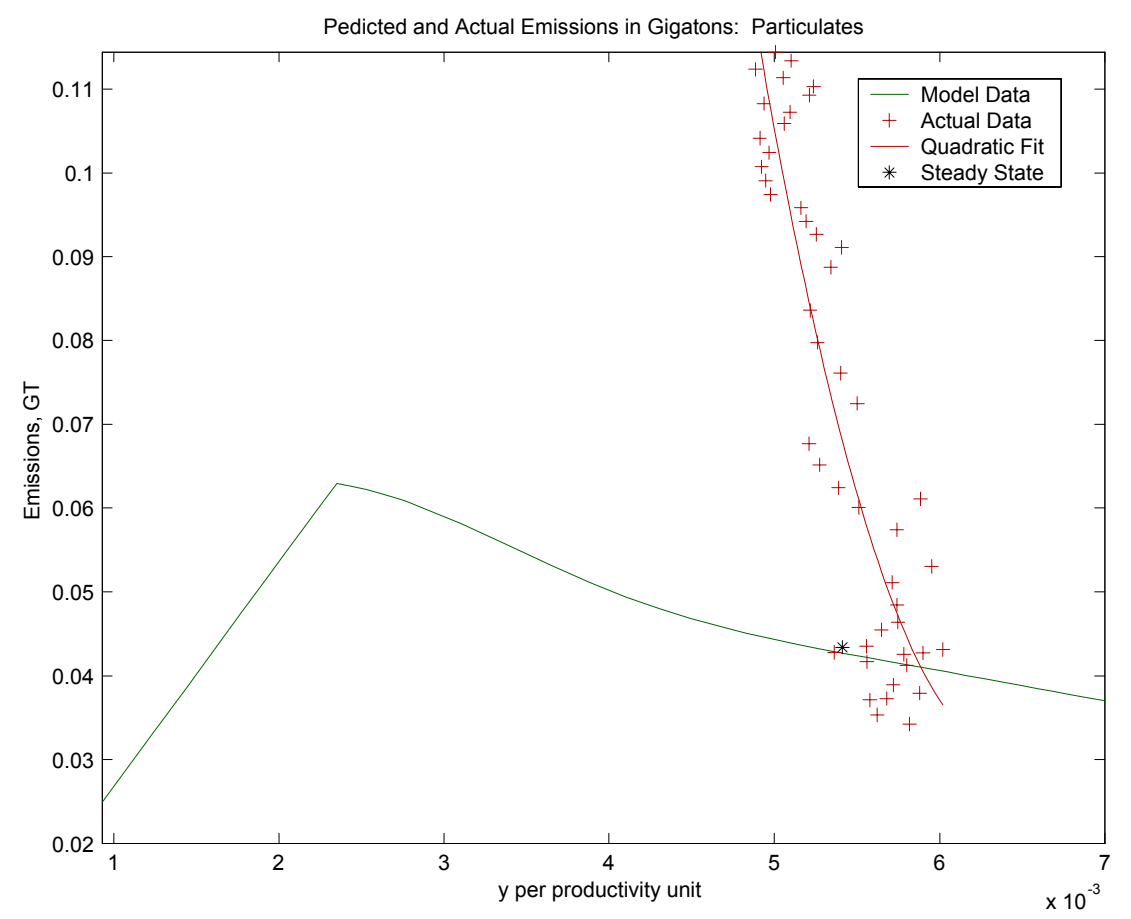

Figure 2: Predicted and actual pollution-income curve for particulates. 


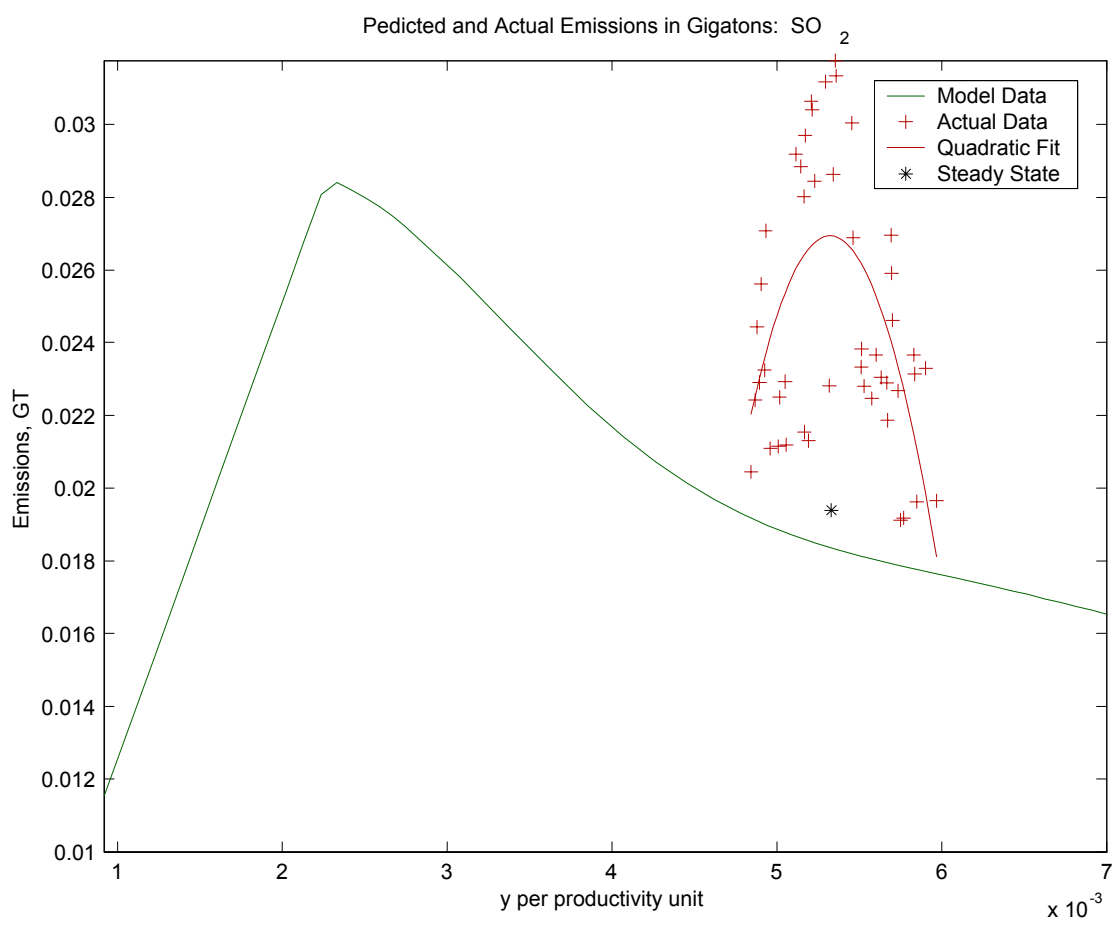

Figure 3: Predicted and actual pollution-income curve: $\mathrm{SO}_{2}$.

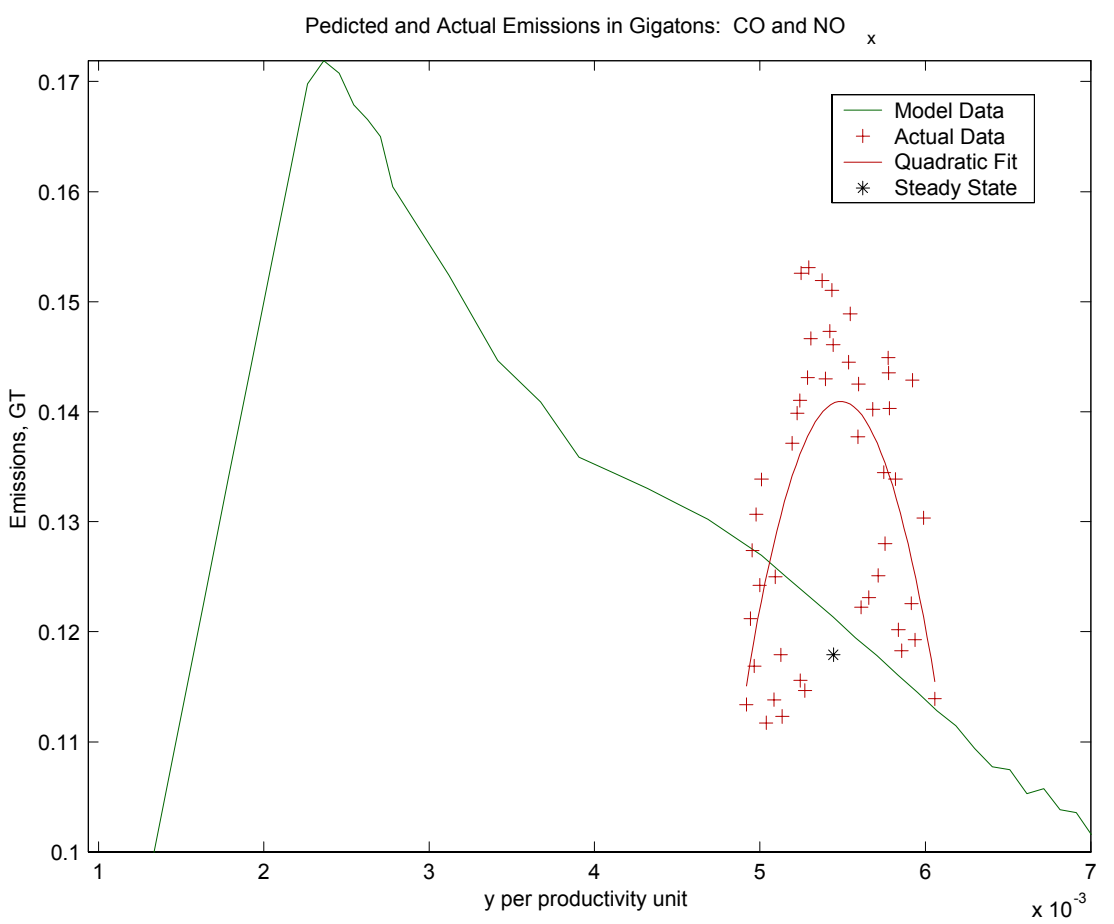

Figure 4: Predicted and actual pollution-income curve: $\mathrm{NO}_{x}$ and $\mathrm{CO}$. 


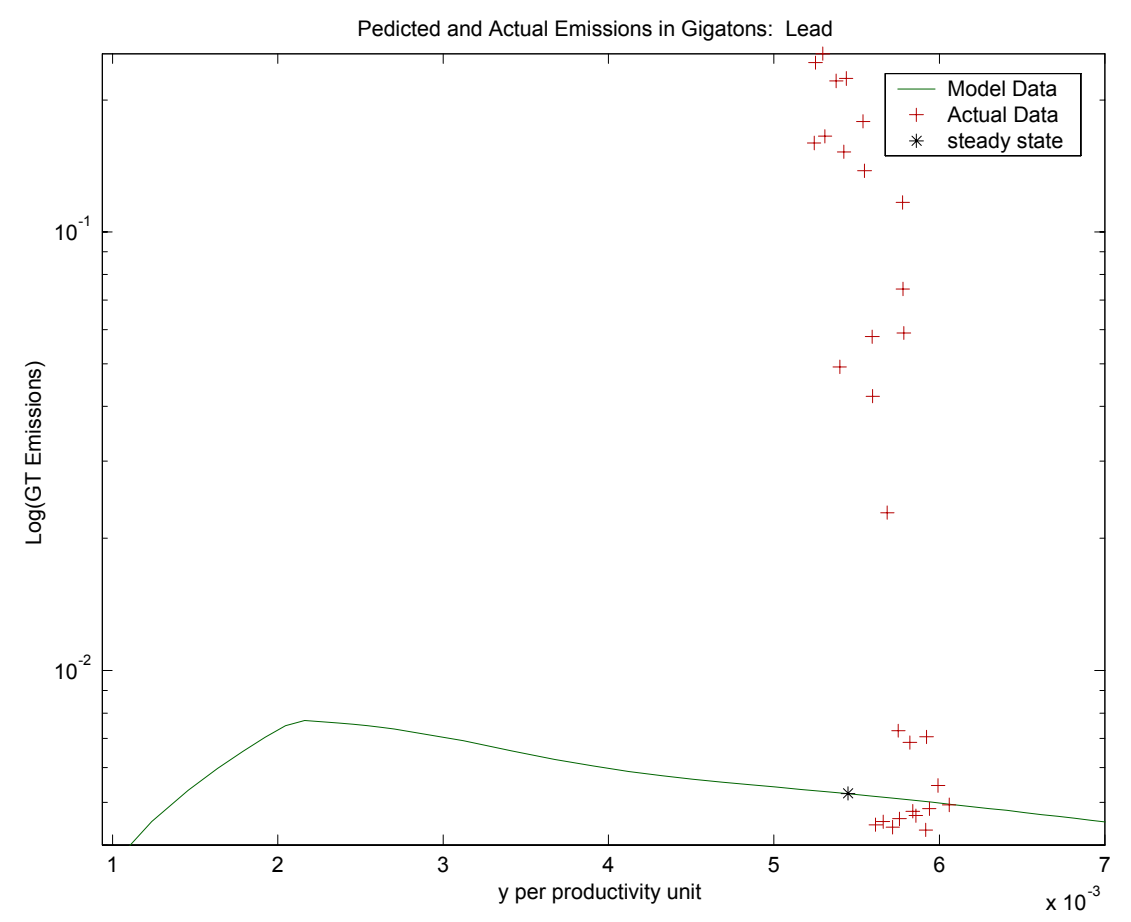

Figure 5: Predicted and actual pollution-income curve: Airborne Lead.

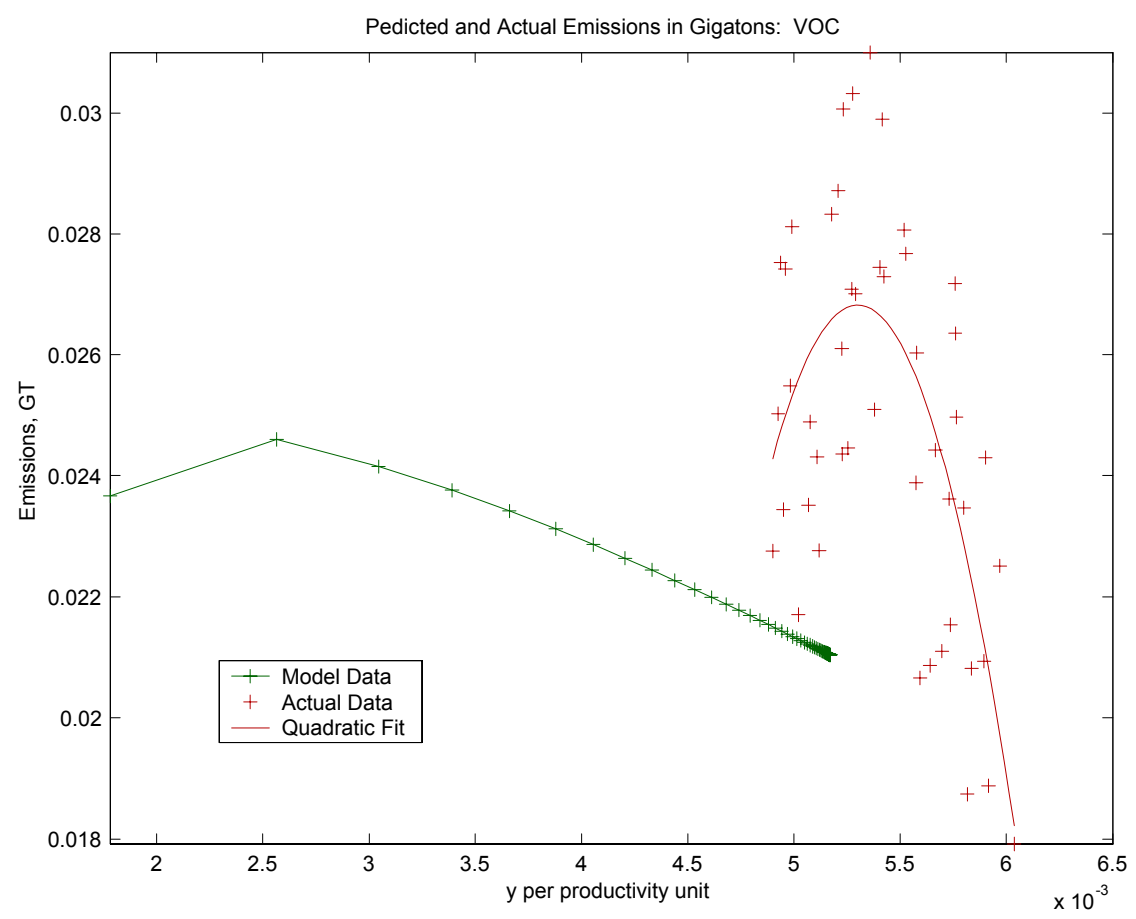

Figure 6: Predicted and actual pollution-income curve: VOC. 


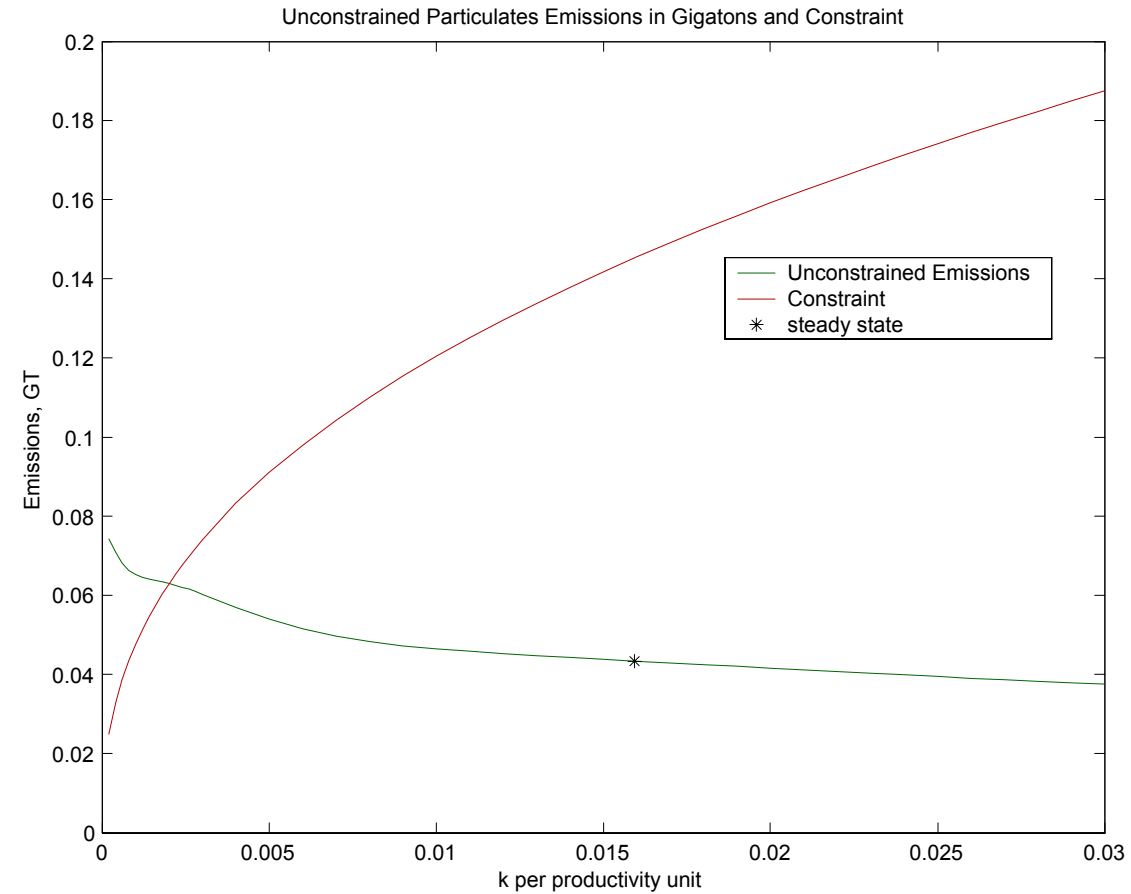

Figure 7: Predicted Pollution-Income Curve: Unconstrained Particulates. 